\title{
The Possibility of Continuous Growth with Exhaustible Resources: Unknowingly an Agreement Has Been Reached, But It May Not Be Correct
}

\author{
by Howard Petith ${ }^{1}$
}

June 2002

Address: Departament d'Economia i d'Història Econòmica, Edifici B, Universitat Autònoma de Barcelona, 08193 Bellaterra Spain. Howard.Petith@uab.es

\begin{abstract}
It is the size of the elasticity of substitution that has been the central issue in the long debate over the possibility of continuous growth in the presence of exhaustible resources. This paper reviews the debate and comes to the surprising conclusion that, unnoticed by the pessimists, the optimist position has gradually evolved so that it now approximates that of the pessimists. The paper also summarises some preliminary work by the author that indicates that this common position may not be correct.
\end{abstract}

JEL Classification: E 13; O 13, 33, 41; Q 30.

Keywords: Exhaustible resources, elasticity of substitution, innovation possibility frontier

\section{Introduction.}

The opening shot in the long debate over the possibility of continual growth with exhaustible resources was the book sponsored by The Club of Rome (Meadows et al (1972)) which claimed that growth would shortly come to an end because of resource exhaustion. The response of the academic community, which was not long in coming, was that the Club of Rome book had overlooked the possibility of capital-resource substitution. Stiglitz (1974) in the essential neo-classical treatment showed that, with population growth, technical progress, exhaustible resources and a Cobb-Douglas production function, the competitive/optimal path would, depending on the parameter values, be characterised by growing per capita consumption.

Two things have happened since. First the neo-classical position, embodied in Stiglitz's paper and one by Solow (1974) which also used a Cobb-Douglas production function, has been attacked. It has been claimed that materials balance and thermodynamic methods imply that the elasticity of substitution must eventually fall below one and that technical progress will be insufficient to permit continual growth of per capita income. Second, and unperceived by the attaching forces, the defenders of continuous growth have gradually shifted their position until, in its most important respects, it coincides with that of the attackers.

\footnotetext{
${ }^{1}$ Thanks go to Deirdre Herrick, to Mordicai Schechter and Joan Martínez Allier for help with the literature, to Xavier Jarque for help with Mathematica for a supporting paper and to Jordi Caballé for comments in the macro workshop of IDEA. Thanks also go to Jon Conrad for suggesting that the literature review part of another paper be published separately. Financial support from DGCYT grants PB95-0130-C02-01 and PB96-1160-C02-02 is acknowledged.
} 
The present paper has a two fold purpose. The main point is to review the debate over the size of the elasticity. This seems worth while both because of the lack of perception of the changing optimist position and because the debate itself seems to have come at least to a standstill. The second and potentially important point is to note that preliminary work by the author (2001) indicates that the current positions of both the optimists and the pessimists may be wrong and that there may be theoretical reasons for thinking that the elasticity of substitution may be exactly one.

Thus the structure of the paper is as follows. First the preliminary work is briefly described then, in the main section, the course of the debate is set out and finally, in a short closing section, the implications of the preliminary work for the subject of the debate are sketched.

\section{Preliminary Work.}

The generalised innovation possibility frontier (GIPF) model of the author shows that there is a process where by the production function of an economy converges over time to either a Cobb-Douglas or a Leontief production function, depending on the initial conditions.

In the model output is produced via a CES production function with two factors. In addition there is a GIPF which describes the way in which the production function may change over time. In particular, there is a trade off between increases in factor productivity and the size of the elasticity of substitution. For example, if a new technology with higher productivity of both factors is chosen, then it will have a lower elasticity of substitution. In this frame work, it is assumed that the technology which maximises the value of current period output in each period is chosen. In this way a sequence of factor productivity growths and elasticities is chosen. The result is that, depending on the initial values, the CES converges either to a Leontief production function with equal constant rates of factor productivity growth or a Cobb-Douglas with different constant rates of growth.

The intention is to use this framework to talk about the problem of continuous growth in the presence of exhaustible resources. On the one hand it is relevant because the essential issue is whether the elasticity of substitution is at least one or not, and this model provides an argument that it may eventually be exactly one. But on the other hand it is clearly deficient in many ways: First, the factors here are fixed flows of services rather than exhaustible stocks; second there are only two factors of production whose levels only change because of technical progress rather than three factors where, in addition to technical progress, labour would grow exogenously, capital would grow via accumulation and land would be fixed. There is a distinct possibility that the mechanism would be preserved if the model was generalised to include some or all of the above points. However this is something that only further research will reveal. 


\section{A Brief Review of the Debate.}

Stiglitz (1979 p36) notes that those who make prognostications of the future can be divided into optimists and pessimists. In the current round of the debate over whether economic activity is threatened by resource scarcity, the focus of the attack of the pessimists has been the papers written by Solow and Stiglitz for the 1974 Review of Economic Studies symposium on exhaustible resources. Both used a Cobb-Douglas and, in addition, Stiglitz assumed positive population growth and technical progress and showed that continual growth of per capita consumption was a distinct possibility. The trick is that, with a Cobb-Douglas, output can grow although the input of resources becomes vanishingly small as long as the quantity of capital grows sufficiently.

This property of the Cobb-Douglas has been attacked by the pessimists as violating the laws of physics. The essential point is that output consists of physical goods which can not be made out of a vanishingly small amount of resources regardless of how much capital is available. This point was initially made by Geogescu-Roegen in a number of publications e.g. $(1975,1979)$. It has intermittently been revived over the years with the most notable reoccurrence being the Georgescu-Roegen versus Solow/Stiglitz forum organised by Daly (1997a,b). In it Daly attacked, Solow and Stiglitz defended and then a large number of interested parties made comments.

While the essential idea of the pessimists is easy to grasp and has often been alluded to, the fashioning of a convincing argument is a considerable challenge which has not often been attempted: It must be shown that regardless of what happens in the future, the laws of physics imply that continuous growth is not possible. Basically there are two approaches, materials balance and thermodynamics, both of which were mentioned by GeorgescuRoegen (1975). The materials balance approach concentrates on the finite quantity of material available on earth, while the thermodynamic approach is based on the fact that production lowers the amount of energy available in a closed system.

The only formal model that uses materials balance to show that continual growth is impossible is that of Gross and Veendorp (1990). They adopt Stiglitz's framework, define output in terms of the exhaustible resource, assume that output can not be greater than the resource input and then show that continual growth of output and consumption is not possible. This in itself is not unexpected, given the finite quantity of resources. What is surprising, however, is that they then add technical progress, the factor that, in Stiglitz's model, allows growing per capita income, and show that in most cases continual consumption growth still is impossible. I think that the result is flawed, ${ }^{2}$ but it is impressive and deserves more interest than it seems to have received.

There are two formal models which attempt to use thermodynamics. The second, by Islam (1984), adds resource scarcity to Houthakker's (1955) demonstration from first

\footnotetext{
${ }^{2}$ A discussion of this is outside the bounds of the paper.
} 
principles that the production function must be Cobb-Douglas. He shows that, with this addition, the elasticity of substitution between resources and capital must be less than one for large outputs. The idea is deep and engaging but the presentation is obscure in the extreme and has not been followed up.

The first by Ayres and Miller (1980) is, to my mind, the only completely convincing formal argument that perpetual growth of consumption and output is impossible. They accept the equivalency of energy and matter and measure all output and all inputs in terms of negentropy (a measure of energy available). Technical progress increases the efficiency of production but, since output and inputs are measured in the same units, there is an upper limit: the output cannot contain more negentropy than the inputs. Their conclusion is that once the minerals of the earth's crust have been exhausted, production cannot exceed the amount of energy received from extraterrestrial sources. Thus, in spite of technical progress, continual growth of production and consumption is impossible.

All three of these contributions derive production functions in which the elasticity of substitution is less than one. The papers by Gross and Veendorp and by Ayres and Miller, which are the ones well connected to the debate, then show that this makes continual growth of consumption and production impossible and that technical progress can not reverse this conclusion. Finally they both see their contributions as rebuttals of the Solow/Stiglitz position. These papers are far from being the most polemic, but I think they must be seen as the heart of the pessimist position.

The pessimists have centred their attacks on a caricature of the optimists and have shown no awareness of the considerable change that has taken place within this camp. For this reason and since no summary of the positions of the optimists exists, ${ }^{3}$ it is worth while reviewing the positions of Solow, Stiglitz and a third contributor to the symposium, Partha Dasgupta.

The basis of Solow's optimism, an optimism which has always appeared as a justification for the framework in which he analyses intergenerational equity, has changed considerably over the years. In (1974a) and (1974b) he thought that continual growth of consumption could be sustained by capital-resource substitution since the elasticity appeared to be greater than one. Then, in a number of papers, (1986), (1993a) and (1993b), his position gradually shifted. In his (1997) note, he still mentions the possibility of capital-resource substitution, but his emphasis is elsewhere. He thinks that growth can be supported "for a long time" by two types of technical progress: that which increases the output of renewable resources like fisheries, and that which allows the use of plentiful exhaustible resources like the development of nuclear fission.

Stiglitz's (1974a) and (1974b) models generated continual growth but contained no justification for the assumption of unitary elasticity. However in his (1979) paper he

${ }^{3}$ For example, two recent surveys, Toman, Pezzey and Krautkraemer (1995) and Stern (1997) contain no detailed description of the optimists' positions. 
completely clarified his position which has, despite some later ambiguity, remained unchanged to the present. He divided the question of continual growth into two: under what conditions was it possible? and are these conditions empirically satisfied? He thought that his (1974) papers had answered the first: the elasticity of substitution had to be at least one and the rate of technical progress had to be sufficient. He thought that only econometricians could answer the second and this only within a horizon of between twenty five to one hundred years. Within this time range he was optimistic about the size of the elasticity since there was no evidence that the share of resources was increasing.

After this he changed his tack and wrote three papers, (1981), (1982) and (1983) with Dasgupta and other authors which utilised the backstop technology. With this one invests in research and, after a time, a substitute of infinite supply is found for the exhaustible resource. The example given was the technical-break through which allowed the substitution of plentiful coal for increasingly scarce timber in nineteenth century British iron manufacture. Since research can be thought of as capital accumulation, this is a complex combination of resource-resource and capital-resource substitution. Unlike pure capital-resource substitution it depends on there being a plentiful supply of alternative resources and, for this reason, it does not justify perpetual growth. On the other hand, given the availability of resources in general, it is an argument in favour of a very long growth horizon.

After this Stiglitz left the issue and only has returned briefly in his (1997) note. In it he mentions resource-resource substitution which is a clear reference to the long run backstop argument. But then he insists that the horizon of fifty to sixty years is the important one and, within this, he emphasises the importance of technical progress that increases the efficiency of resource use and his optimism over the possibility of capitalresource substitution. Thus, with some ambiguity, he seems largely to have returned to the position he took in his (1979) paper.

The views of the third of the optimists, Partha Dasgupta, are characterised, first, by a consistently long run perspective, second by a move from optimism to pessimism over the elasticity and third, by the reverse move with regard to technical progress. Dasgupta, along with Geoffrey Heal wrote one of the 1974 symposium papers and a book in 1979. The (1974) paper noted that the elasticity of substitution was important for planning, that on current evidence its value was greater than one, but that there was no way of knowing its value for resource-capital ratios outside the historic range (p206). In the book the position is strengthened. Their justification of the assumption of a constant population, the finite size of the world, shows that they are focusing on long run problems. They identify the elasticity of substitution as the key variable: if it is greater than one there is no problem while if it is less there is no way to avoid doom (pp 199-200). They think that the backstop model is the correct way to model technical progress in relation to resources but are generally pessimistic: " Perpetual technical progress, while unlikely, is not an absurd 
notion" (p199 and also p206). With regard to the size of the elasticity, they are equivocal but generally optimistic. They note (p206) that currently the value seems to be greater that one but they caution against extrapolation. Then, in their discussion of thermodynamics, they say that these considerations imply an elasticity less than one (p211). But immediately after this they justify their continued use of the Cobb-Douglas by arguing in an unclear way that energy is included in capital so that the shapes of the isoquants can not be determined by thermodynamic considerations. Thus, while the argument is muddy, the tone is decidedly optimistic with regard to the size of the elasticity of substitution.

Dasgupta then moved away from optimism about the elasticity of substitution between capital and resources and toward optimism about the possibility of sustained growth supported by technical progress which permitted the substitution of exhaustible resources which are scarce by those which are plentiful. First between 1977 and 1983, he coauthored at least four papers on the backstop technology, (1977), (1981), (1982) and (1983). Then in 1993 he published what might be called a position paper on the subject. He started by clearly identifying himself as an elasticity pessimist, claiming that, for high resource-capital ratios, the elasticity of substitution was less than one, citing in support (with a short memory lapse) the section on thermodynamics in his joint book. Then he made three points: First, the substitution that is important is not capital-resource but that of plentiful for scarce resources, a process which requires increases in technical knowledge. Second the working of markets will provide incentives for the prerequisite technical progress to take place. And third, that the totality of minerals in the earth's crust, with the exception of phosphate rock (1300 years), fossil fuels (2500 years) and manganese (13,000 years) are sufficient, at the current rate of use, for at least the next million years. Thus Dasgupta's position is, with the recycling of phosphate and manganese and the development of cheap energy sources, that the world should not experience problems due to resource shortages in this time scale.

To summarise the development of the three optimists: Solow and Dasgupta moved from the position that perpetual growth was possible because of capital-resource substitution to the position that growth is possible for a long period, a million years according to Dasgupta, because of a combination of capital investment in research and resourceresource substitution. Stiglitz flirted with this view, but has largely returned to the position that the hundred year horizon is the only one of interest for predictions and that, within this horizon, technical progress and the elasticity of substitution are such that there will be no resource scarcity induced crisis.

What is the actual state of the debate? Pezzey (1992 p339) has characterised it as being between two models, one which permits sustained growth (e.g. Dasgupta and Heal (1979)) and one that does not (eg. Ayres and Miller (1980)) and then calls for empirical research 
to decide which assumptions are more justified ${ }^{4}$. I disagree. Rather I think that it is the level of the time scale that distinguishes the participants ${ }^{5}$ and that it is disinterest and, at times, incomprehension rather than disagreement which characterizes the debate. At the lowest time scale come Stiglitz, a large group of resource econometricians and the advocates of sustainability, whose works are respectively reviewed by Slade, Kolstad and Weiner (1993) and by Toman, Pezzey and Krautkraemer (1995) and Stern (1997). Each of these participants has shown only minimal interest in the works of the others. In particular it is noteworthy that the econometricians, although they have the techniques (if perhaps not the data) have completely eschewed any attempt to answer the elasticity question that Stiglitz posed. At the next level come Solow and Dasgupta and at the last level, where material balance and thermodynamic considerations become important, come the pessimists for whom, some what unjustly, Georgescu-Roegen and Daly may be taken as spokesmen. ${ }^{6}$ Georgescu-Roegen (1979) agrees that econometric techniques cannot be used for long run elasticity estimation but criticises Stiglitz's hundred year horizon as being too short to be of interest and claims that material balance and thermodynamic methods will allow the longer horizon to be studied. Solow (1997), replying to Daly's (1997a) call for the use of these tools, states that the required time horizon is too long for the results to be of "practical interest". One would expect that Daly, in his reply (1997b), would argue that the horizon is, indeed, short enough. But instead he reacts as if Solow were at the last level and was merely unaware of the difficulties that this causes for his Cobb-Douglas production function. The same inability to engage the opponent characterises Ayres and Miller's (1980) criticism of Stiglitz's hundred year horizon and Gross and Veendorp's (1990) criticism of the optimist position generally. They use the tools of the last level to attack the optimists without seeming to realise that it is the relevance of the level that must be defended. At the level where material balance and thermodynamic considerations become important, everyone who has expressed an opinion is already an elasticity pessimist.

\section{The Implications of the Preliminary Work.}

If further work confirms that the elasticity of substitution should converge to either zero or one also for more general models, this will have strong implications for the debate. In this case we should expect that in the long run the production function will approximately be either Leontief or Cobb-Douglas. This goes against the positions of all

\footnotetext{
${ }^{4}$ Pearce (1997 p.295) also says that the elasticity of substitution is an empirical issue.

5 This distinction is noted by vanden Bergh and Mooij (1999). They give the time horizon of the technocrats, of which presumably Dasgupta is one, as short to medium.

${ }^{6}$ One need only read the contributions of the interested parties in the forum to get a flavour of the disagreement in the pessimist camp.
} 
the participants in the debate with the exception of Stiglitz who considered only a hundred year horizon. How can all of these participants have been wrong?

First, there are the group who view the elasticity of substitution as a parameter to be established by econometric techniques. It is a common opinion of this group that these techniques can not establish the value of the parameter for the high capital-resource ratios that will be relevant for the future exactly because we do not, now, have data in that range, e.g. Georgescu-Roegen (1979), Dasgupta and Heal (1979 p206) and Slade, Kolstad and Weiner (1993 p959). This lack of long run relevance might be thought to excuse the absence of econometric attempts to answer the elasticity question. But this general position is incorrect. The preliminary work provides a testable hypothesis: if there is a difference between the rates of productivity growth of the various factors then one ought to observe a convergence of the elasticity. If this was confirmed, one would have econometric evidence that the long run value of the elasticity is one, even outside the range of the data. ${ }^{7}$

Second, there is a large group of pessimists that hold that for high values of the capitalresource ratio the elasticity of substitution must be less than one for materials balance or thermodynamic reasons. These include Dasgupta (1993 p1115), Ayers (1978 chap.3), Ayers and Miller (1980), Gross and Veendrop (1990) and clearly Daly (1997a,b). The preliminary work implies that these authors are incorrect as well in the sense that, depending on the initial conditions, the elasticity may well be one. Since this conclusion seem to fly in the face of physical science it requires some justification.

How can a growing quantity of output be made with a vanishingly small quantity of resources? The answer lies in what we mean by output. Both Ayres and Miller (1980) and Gross and Veendrop (1990) defined output in terms of a physical characteristic. They were forced to do this in order to demonstrate that continuous growth was not possible. But output is, rather, an index of a bundle of goods which change with a movement along an isoquant and which are only related by the fact that they all give the same utility to the consumer. ${ }^{8}$ It is not hard to imagine that, as one moves along an isoquant, the bundle changes in such a way that a constant utility is produced by a vanishingly small amount of resources so long as the amount of capital is sufficiently large. This point was first made by Ayres (1978, chap.3), reiterated by Stiglitz (1997 p267) and is the main justification for the recent spate of resource-endogenous growth papers surveyed by Smulders (1995,

\footnotetext{
7 The large literature on empirical testing of the induced innovation hypothesis is of little relevance because the best papers estimate translog production functions for which the elasticity of substitution varies with factor inputs. See Thirtle and Rutton (1987) for a survey. But recently Thirtle, Townsend and van Zyl (1998) have approached the problem differently. They use a CES production function, cointegration and error correction. Thus they get an estimate of the long run elasticity of substitution. The theoretical basis of their work is slightly different and they assume that the elasticity does not change over time, but it seems that their work could be modified to test the convergence hypothesis of the preliminary work.

${ }^{8}$ This can be formalised using the notion of an exact quantity index which is explained by Diewert (1993) for example.
} 
1999). What the preliminary work implies is that technical progress will be just such as to reveal those techniques which ensure that the elasticity of substitution will be exactly one.

Apart from indicating where the positions of the participants may be incorrect, what is the positive contribution of the preliminary work to the debate? It is to show that the size of the elasticity is completely irrelevant to the question of whether constant or growing per capita consumption is possible. To put the point as strongly as possible consider the following. Suppose the production function is Cobb-Douglas, the productivity of the other factors is growing much faster than that of land and, due to an increase in the cost of producing elasticity connected with increasing resource scarcity, the rate of growth of output has dropped below that of population growth. From the perspective of the participants in the debate one would be tempted to say," Its lucky that the elasticity is one because, if it fell even slightly, the rate of growth would drop precipitously to that of the productivity of land". But this statement completely misunderstands the situation since it is exactly the increased cost of keeping the elasticity equal to one that has caused the problem in the first place.

\section{References.}

Ayres, R.U. (1978). Resources, Environment and Economics: Applications of Material/Energy Balance Principles. New York: John Wiley \& Sons.

Ayres, R.U. and S. Miller, (1980). The Role of Technical Change. Journal of Environmental Economics and Management, 7, 353-71.

Daly, H.E. (1997a). Forum, Georgescu-Roegen versus Solow/Stiglitz. Ecological Economics, 22, 261-66.

Daly, H.E. (1997b). Forum, Reply to Solow/Stiglitz. Ecological Economics, 22, 271-3.

Dasgupta, P. (1993). Natural Resources in an Age of Substitutability. In A.V. Kneese and J.L. Sweeney (eds), Handbook of Natural Resource and Energy Economics, Vol. III. Amsterdam: Elsevier, 1111-30.

Dasgupta, P., R.J. Gilbert and J.E. Stiglitz, (1982). Invention and Innovation under Alternative Market Structures: The Case of Natural Resources. Review of Economic Studies, 69, 567-82.

Dasgupta, P., R.J. Gilbert and J.E. Stiglitz, (1983). Strategic Considerations in Invention and Innovation: The Case of Natural Resources. Econometrica, 51, 1439-48.

Dasgupta, P. and G. Heal, (1974). The Optimal Depletion of Exhaustible Resources. Review of Economic Studies, symposium, 3-28.

Dasgupta, P. and G. Heal, (1979). Economic Theory and Exhaustible Resources. Cambridge: Cambridge University Press. 
Dasgupta, P., G. Heal and M. Majumdar, (1977). Resource Depletion and Research Development. In M.D. Intriligator (ed), Frontiers of Quantitative Economics, Vol III, Amsterdam: North-Holland, 483-505.

Dasgupta, P. and J.E. Stiglitz, (1981). Resource Depletion under Uncertainty. Econometrica 49, 85-104.

Diewert, W.E. (1993). Index Numbers. In W.E. Diewert and A.O. Nakamara, (eds.), Essays in Index Number Theory vol. 1, Amsterdam: Elsevier Science Publishers, 71104.

Duménil, G. and D. Lévy (1995). A Stocastic Model of Technical Change: An Application to the US Economy (1869-1989), Metroeconomica 46, 213-45.

Georgescu-Roegen, N. (1975). Energy and Economic Myths. Southern Economic Journal, 41, 347-81.

Georgescu-Roegen, N. (1979). Comments on the Papers by Daly and Stiglitz. In V.K. Smith (ed), Scarcity and Growth Reconsidered, Baltimore: Johns Hopkins Press, 95105.

Gross, L.S. and E.C.H. Veendorp, (1990). Growth with Exhaustble Resources and a Materials-Balance Production Function. Natural Resource Modeling, 4, 77-93.

Houthakker, H.S. (1955). The Parato Distribution and the Cobb-Douglas Production Function in Activity Analysis. The Review of Economic Studies, 19, 27-31.

Islam, S. (1985). Effect of an Essential Input on Isoquants and Substitution Elasticities. Energy Economics, 194-6.

Meadows, D.H., D.L. Meadows, J. Ronders and W.W. Behrens III (1972). The Limits to Growth. New York: Universe Books.

Pearce, D. (1997). Substitution and Sustainability: Some Reflection on GeorgescuRoegen. Ecological Economics 22, 295-7.

Petith, H. (2001). Georgescu-Roegen versus Solow/Stiglitz and the Convergence to the Cobb-Douglas. W.P.489.01, Departament d'Economia i d'Història Econòmica i Institut d'Anàlisi Econòmica,CSIC ,UAB. Downloadable at http://pareto.uab.es/wp

Pezzey, J. (1992). Sustainability: An Interdisciplinary Guide. Environmental Values, 1. 321-62.

Slade, M., C. Kolstad and R. Weiner, (1993). Buying Energy and Non-Fuel Minerals. In A.V. Kneese and J.L. Sweeney (eds), Handbook of Natural Resource and Energy Economics, Vol. III. Amsterdam: Elsevier, 935-1009.

Smulders, S. (1995). Entropy, Environment and Endogenous Growth. International Tax and Public Finance, 2 319-40.

Smulders, S. (1999) Endogenous Growth Theory and the Environment, chap. 42 in J.C.J.C. van den Bergh, (ed.) Handbook of Environmenttal and Resource Economics. Cheltenham: Edward Dlgar Publishing Ltd. 609-21.

Solow, R.M. (1974a). Intergenerational Equity and Exhaustible Resources. Review of Economic Studies, symposium, 29-45. 
Solow, R.M. (1974b). The Economic of Resources or the Resources of Economics. The American Economic Review, 64 (May),1-14.

Solow, R.M. (1986). On the Intergenerational Allocation of Natural Resources. Scandinavian Journal of Economics, 88, 141-9.

Solow, R.M. (1993a). Sustainability: An Economist's Perspective. In R. Dorfman and N. Dorfman (eds), Selected Readings in Environmental Economics, 3rd Edition, New York: Norton, 179-87.

Solow, R.M. (1993b). An Almost Practical Step Toward Sustainablilty. Resources Policy $19,162-72$.

Solow, R.M. (1997). Reply, Georgescu-Roegen versus Solow/Stiglitz. Ecological Economics, 22, 267-8.

Stern, D.I. (1997). Limits to Substitution and Irreversibility in Production and Consumption: A Neoclassical Interpretation of Ecological Economics. Ecological Economics, 21, 197-215.

Stiglitz, J.E. (1974a). Growth with Exhaustible Natural Resources: Efficient and Optimal Growth Paths . Review of Economic Studies, symposium, 123-37.

Stiglitz, J.E. (1974b). Growth with Exhaustible Natural Resources: The Competitive Economy. Review of Economic Studies, symposium, 123-57.

Stiglitz, J.E. (1979). A Neoclassical Analysis of the Economics of Natural Resources. In V.K. Smith (ed), Scarcity and Growth Reconsidered, Baltimore: Johns Hopkins Press, 36-66.

Stiglitz, J. (1997). Reply, Georgescu-Roegen versus Solow/Stiglitz, Ecological Economics, 22, 269-70.

Thirtle, C. and V.W. Ruttan (1987). The Role of Demand and supply in the Generation and Diffusion of Technical change. Fundamentals of Pure and Applied Economics, Vol. 21. London: Harwood Academic Publishers.

Thirtle, C., R. Townsend and J.van Zyl (1998). Testing the Induced Innovation Hypothesis: An Error Correction Model of south African Agriculture. Agricultural Economics 19, 145-57-

Toman, M.A., J. Pezzey and J. Krautkraemer, (1995). Neoclassical Economic Growth Theory and "Sustainability". In D.W. Bromley (ed), The Handbook of Environmental Economics, Oxford: Blackwell, 139-65. 